\title{
SAN096-04/1C CONF-960954--1 \\ HYDRODYNAMIC CHARACTERIZATION OF \\ SLURRY BUBBLE-COLUMN REACTORS \\ FOR FISCHER-TROPSCH SYNTHESIS
}

\author{
N. B. JACKSON ${ }^{1}$, J. R. TORCZYNSKI 2 , K. A. SHOLLENBERGER ${ }^{2}$, \\ T. J. O'HERN ${ }^{2}$, AND D. R. ADKINS ${ }^{2}$ \\ ${ }^{1}$ Advanced Energy Technology Center \\ ${ }^{2}$ Engineering Sciences Center \\ Sandia National Laboratories \\ Albuquerque, NM 87185-5800 USA
}

\section{ABSTRACT}

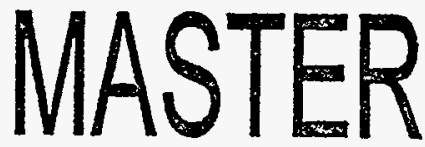

Sandia's program to develop, implement, and apply diagnostics for hydrodynamic characterization of slurry bubble-column reactors (SBCRs) at industrially relevant conditions is discussed. Gas-liquid flow experiments are performed in an industrialscale stainless steel vessel. Gamma-densitometry tomography (GDT) is applied to make spatially resolved gas holdup measurements. Both water and Drakeol 10 with air sparging are examined at ambient and elevated pressures. Gas holdup increases with gas superficial velocity and pressure, and the GDT values are in good agreement with values from differential pressure (DP) measurements.

\section{INTRODUCTION}

In the Fischer-Tropsch approach to indirect liquefaction, slurry bubble-column reactors (SBCRs) are used to convert coal syngas into the desired product. However, gas distribution nonuniformity can cause buoyancy-driven flow, which reduces gas residence time and process efficiency. Thus, it is essential to characterize the gas distribution, particularly as affected by gas flow rate, slurry thermophysical properties, sparger geometry, and, most important for scaling considerations, reactor diameter. To this end, Sandia is developing, implementing, and applying diagnostics for hydrodynamic characterization of SBCRs at industrially relevant conditions [1-5].

\section{INDUSTRIAL-SCALE SBCR TESTBED}

An SBCR apparatus has been constructed as a testbed for diagnostics development and acquiring data under industrially relevant conditions. The SBCR vessel, shown in Figure 1 [3], is made out of stainless steel and has a 48-cm ID, a 3-m height, and a $1.27-\mathrm{cm}$-thick wall. It can operate at pressures up to $100 \mathrm{psig}$ and temperatures up to $200^{\circ} \mathrm{C}$, which are achieved via an in-line gas heater and external heaters controlled at four vertical locations. Two instrumentation ports and two view ports are centered at each of six vertical positions $45.7 \mathrm{~cm}$ apart. Differential pressure (DP) transducers are mounted at each of these positions to measure the vertical pressure gradient, 


\section{DISCLAIMER}

Portions of this document may be illegible in electronic image products. Images are produced from the best available original document. 
from which the average gas holdup between adjacent transducers can be inferred [3]. Prior to operation, the vessel is partially filled with liquid. Gas is injected through one of several interchangeable spargers near the bottom of the vessel. The current sparger is a 15-cm-diameter ring formed from $1.1-\mathrm{cm}-\mathrm{ID}$ stainless steel tubing with twelve $0.3175-\mathrm{cm}$-diameter holes in the top surface. To date, gas superficial velocities up to $0.40 \mathrm{~m} / \mathrm{s}$, gas holdups up to 0.4 , and pressures up to $50 \mathrm{psig}$ have been examined in the SBCR vessel for water and Drakeol 10 with air sparging.

\section{GAMMA-DENSITOMETRY TOMOGRAPHY (GDT) SYSTEM}

A GDT system, including a gamma source and detector and axisymmetric tomographic reconstruction software, has been implemented [1-3]. GDT measures the distribution of the attenuation coefficient of gamma photons, which is linearly related to the gas holdup distribution. A beam of gamma photons is passed through the unknown distribution along several different but coplanar paths, and an axisymmetric tomographic algorithm is employed to reconstruct the gas holdup distribution that gave rise to the measured attenuation values. A 5-Curie Cs-137 isotope source ( $0.6616 \mathrm{MeV}$ photons) in a cylindrical lead vault is used, with a smalldiameter aperture $(0.635 \mathrm{~cm})$ for collimation. The individual gamma photons are observed with a sodium iodide (Nal) scintillation detector, the temperature of which is controlled to minimize thermally induced drift. To avoid spurious acquisition of scattered gamma photons, a small-diameter aperture $(0.3175 \mathrm{~cm})$ is placed in front of the detector. The source and the detector are mounted on two opposing arms of a heavy-duty computer-controlled two-axis traverse, which has $60 \mathrm{~cm}$ of travel in both the horizontal and the vertical directions and $66 \mathrm{~cm}$ of clearance between arms.

\section{SBCR EXPERIMENTAL RESULTS}

Experiments have been performed in the SBCR vessel using water and Drakeol 10 with air sparging. The vessel is filled to four diameters above the sparger prior to sparging, and GDT scans are taken two diameters above the sparger. Additionally, differential pressure (DP) transducers are used to measure the vertical pressure gradient, from which average gas holdup values can be inferred for the volume between transducers. Figure 2 shows the DP gas holdup results for water and Drakeol 10 at gas superficial velocities up to $0.25 \mathrm{~m} / \mathrm{s}$ and pressures up to $50 \mathrm{psig}$, along with the Zuber-Findlay correlation [6]:

$$
\varepsilon_{G}=\frac{j_{G}}{C_{0} j_{G}+C_{1}\left[\sigma g\left(\rho_{L}-\rho_{G}\right) / \rho_{L}^{2}\right]^{1 / 4}}
$$

where $C_{0}$ and $C_{1}$ are empirical coefficients, $\varepsilon_{G}$ is the average gas holdup, $j_{G}$ is the gas superficial velocity, $\rho_{L}$ and $\rho_{G}$ are the liquid and gas densities, $\sigma$ is the surface tension, and $g$ is the gravitational acceleration. Figure 3 shows the results of one GDT scan (both the raw data and the reconstructed profile of gas holdup), and Figure 4 shows gas holdup radial profiles for water and Drakeol 10 as functions of gas superficial velocity and pressure. For both, increasing the pressure increases the overall gas holdup without appreciably changing the shape of the profile whereas increasing the velocity also changes the shape of the profile somewhat. Average gas holdup values are in agreement with the values from DP measurements (Figure 2). 


\section{ADDITIONAL DIAGNOSTIC TECHNIQUES}

For gas-liquid-solid flows like slurry Fischer-Tropsch, additional information is needed beyond GDT to determine the distribution of all three phases. Electrical-impedance tomography (EIT) can potentially provide this. In EIT, electrodes are placed around the vessel's inner perimeter. Current flows between two electrodes, and the resulting voltages are measured at the remaining electrodes. A reconstruction algorithm uses the measured voltages to determine the electrical conductivity distribution, which is related to the distribution of the phases. EIT electronics, hardware, and software have been implemented [4-5]. The EIT hardware consists of a lucite cylinder with 16 strip electrodes mounted on its inner surface. Validation experiments were performed by placing a PVC cylinder within the lucite cylinder at two different locations and filling the remaining annular region with water. A two-dimensional finite element method electrical impedance tomography code called FEMEIT [4-5] successfully determined the size and location of the PVC cylinder for both cases, as shown in Figure 5.

In addition to gas holdup, bubble-size information is also important for reactor hydrodynamics characterization. To this end, a small electrical bubble probe has been fabricated. This probe consists of two needlelike electrodes with a $0.127 \mathrm{~cm}$ separation, similar to the bubble size. The interception of bubbles is recorded as an interruption of electrical current flowing between the electrodes. Figure 6 shows a history of the voltage difference between the electrodes. Large saturated peaks result when both electrodes intercept the bubble simultaneously, whereas smaller peaks correspond to interception by only one electrode or to near misses. Correlation of RMS bubble-probe voltage data with pressure-gradient data is also shown in Figure 6 . Since the pressure gradient correlates strongly with gas holdup, the bubble probe can also be used to measure gas holdup locally (after calibration).

\section{CONCLUSIONS}

Gamma-densitometry tomography (GDT) has been applied to make spatially resolved measurements of the gas holdup in both water and Drakeol 10 at elevated pressures in a 48-cm-diameter SBCR vessel. Future efforts will focus on applying GDT to gain a better understanding of SBCR hydrodynamic behavior and on developing additional diagnostic techniques to better characterize bubble size and to enable three-phase flow measurements.

\section{ACKNOWLEDGMENTS}

This work was performed at Sandia National Laboratories, supported by the U.S. Department of Energy under contract number DE-AC04-94AL85000. The excellent technical support provided by Thomas W. Grasser, John J. O'Hare, and C. Buddy Lafferty is highly appreciated. The authors gratefully acknowledge many interactions with Bernard A. Toseland and Bharat L. Bhatt of Air Products and Chemicals, Inc.

\section{REFERENCES}

1. K. A. Shollenberger, J. R. Torczynski, D. R. Adkins, T. J. O'Hern, and N. B. Jackson, "Gamma densitometry tomography of gas holdup spatial distribution in industrial scale bubble columns," Chem. Eng. Sci., 1996, accepted. 
2. J. R. Torczynski, D. R. Adkins, K. A. Shollenberger, and T. J. O'Hern, "Application of gamma-densitometry tomography to determine phase spatial variation in twophase and three-phase bubbly flows," in: J. Katz (Ed.), Cavitation and Multiphase Flow, ASME, New York, 1996, in press.

3. D. R. Adkins, K. A. Shollenberger, T. J. O'Hern, and J. R. Torczynski, "Pressure effects on bubble column flow characteristics," in: S. Z. Rouhani et al. (Eds.), Instrument and Measurements Symposium, ANS, LaGrange Park, 1996, in press.

4. T. J. O'Hern, J. R. Torczynski, S. L. Ceccio, A. L. Tassin, G. L. Chahine, R. Duraiswami, and K. Sarkar, "Development of an electrical impedance tomography system for an air-water vertical bubble column," in: J. W. Hoyt et al. (Eds.), Measurement Techniques in Multiphase Flows, ASME, New York, 1995, 531-537.

5. J. R. Torczynski, T. J. O'Hern, K. A. Shollenberger, S. L. Ceccio, and A. L. Tassin, "Finite element method electrical impedance tomography for phase distribution determination in multiphase flows: validation calculations and experiments," in: J. Katz (Ed.), Cavitation and Multiphase Flow, ASME, New York, 1996, in press.

6. N. Zuber and J. A. Findlay, "Average volumetric concentration in two-phase flow systems," Journal of Heat Transfer, 1965, 453-468.

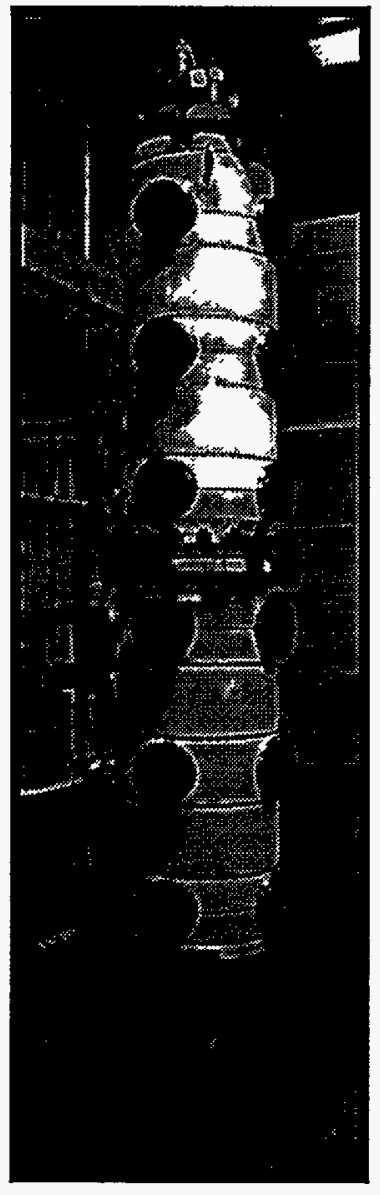

Figure 1. Sandia's slurry bubble-column reactor (SBCR) vessel (48-cm ID, 3-m height, pressures to 100 psig, temperatures to $200^{\circ} \mathrm{C}$, high gas flow rate).
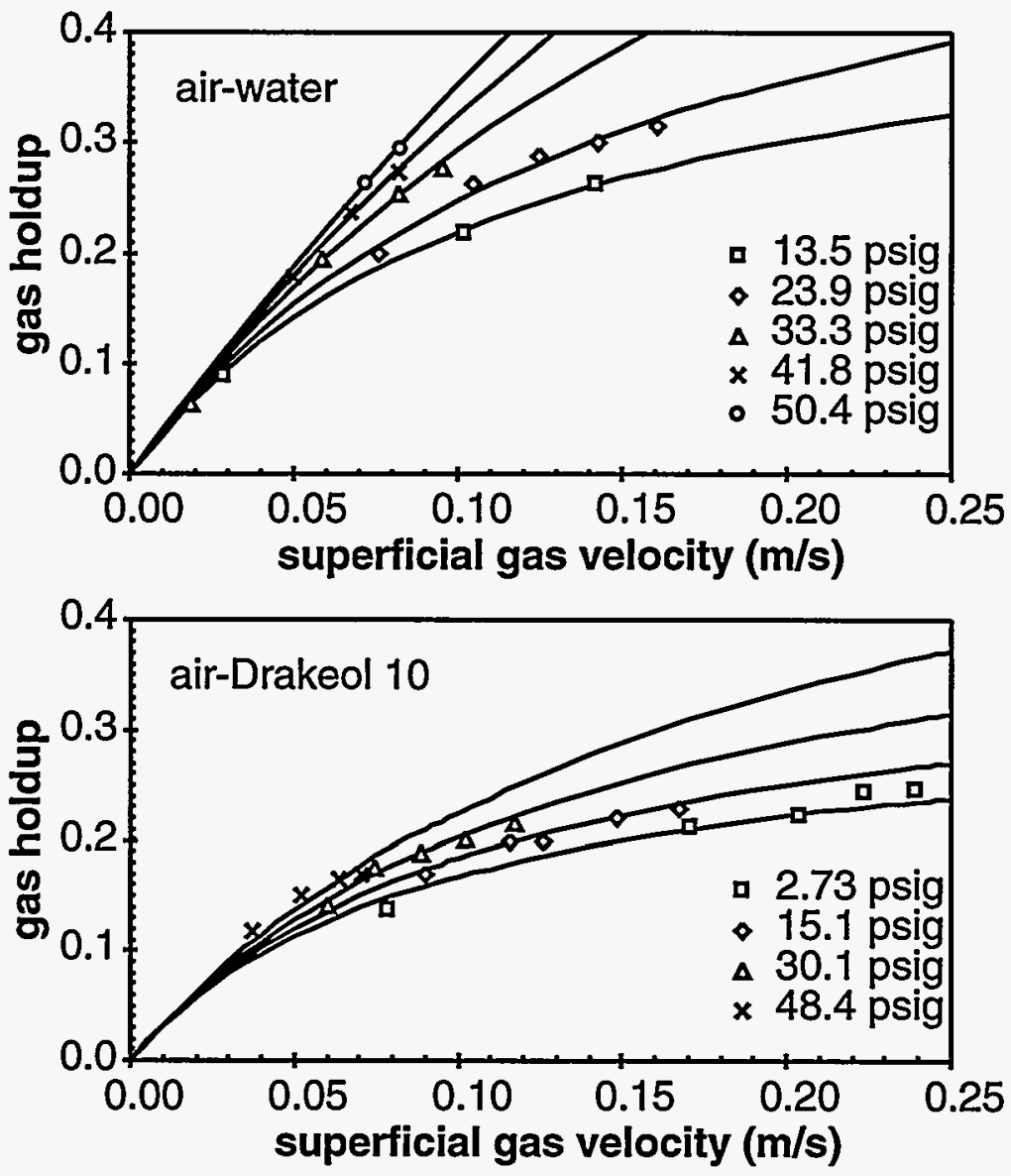

Figure 2. Average gas holdup dependence on gas superficial velocity and pressure in the SBCR vessel from differential pressure measurements for air-water $\left[C_{0}=4.58 \exp (-0.050 p)\right.$ and $\left.C_{1}=1.53\right]$ and for airDrakeol $10\left[C_{0}=3.19 \exp (-0.015 p)\right.$ and $\left.C_{1}=2.13\right]$, with pressure $p$ in psig, for Zuber-Findlay relation [6]. 

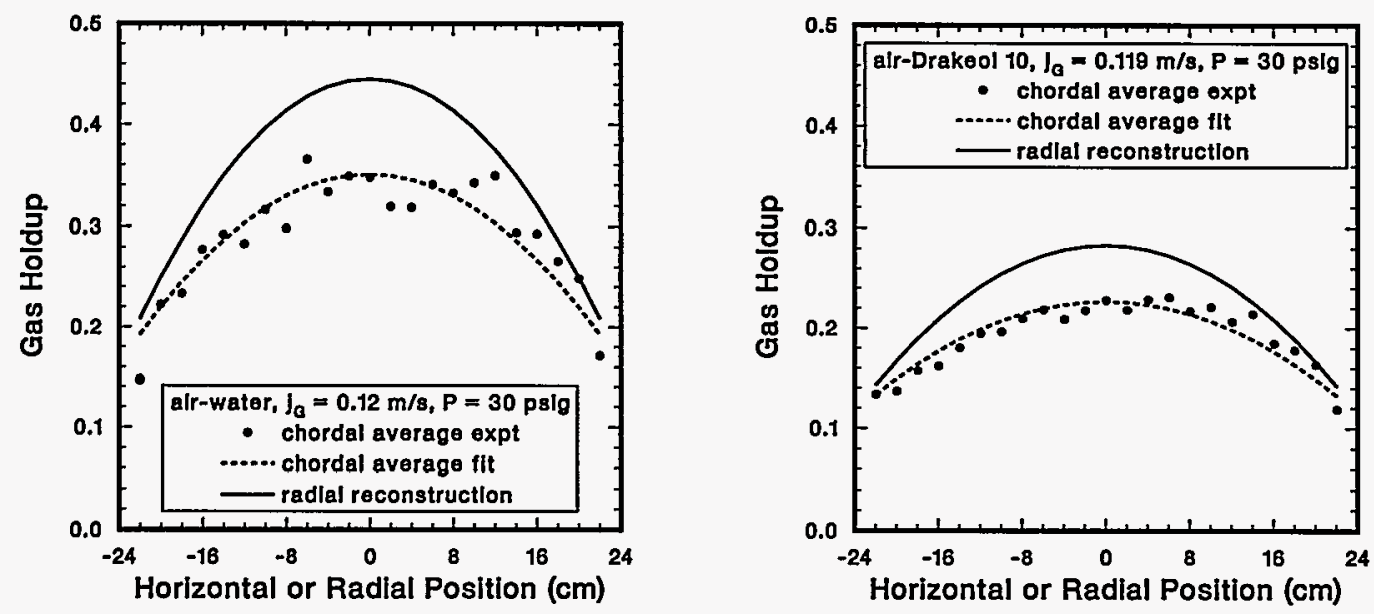

Figure 3. GDT scan two diameters above the SBCR vessel sparger for air-water (left, $30 \mathrm{~s}$ counting time per point) and air-Drakeol 10 (60 s counting time per point): solid circles are experimental chordal averaged values; dashed curve is quadratic radial polynomial fit to experimental values; solid curve is radial reconstruction of gas holdup profile. The slight asymmetry may be related to the sparger.
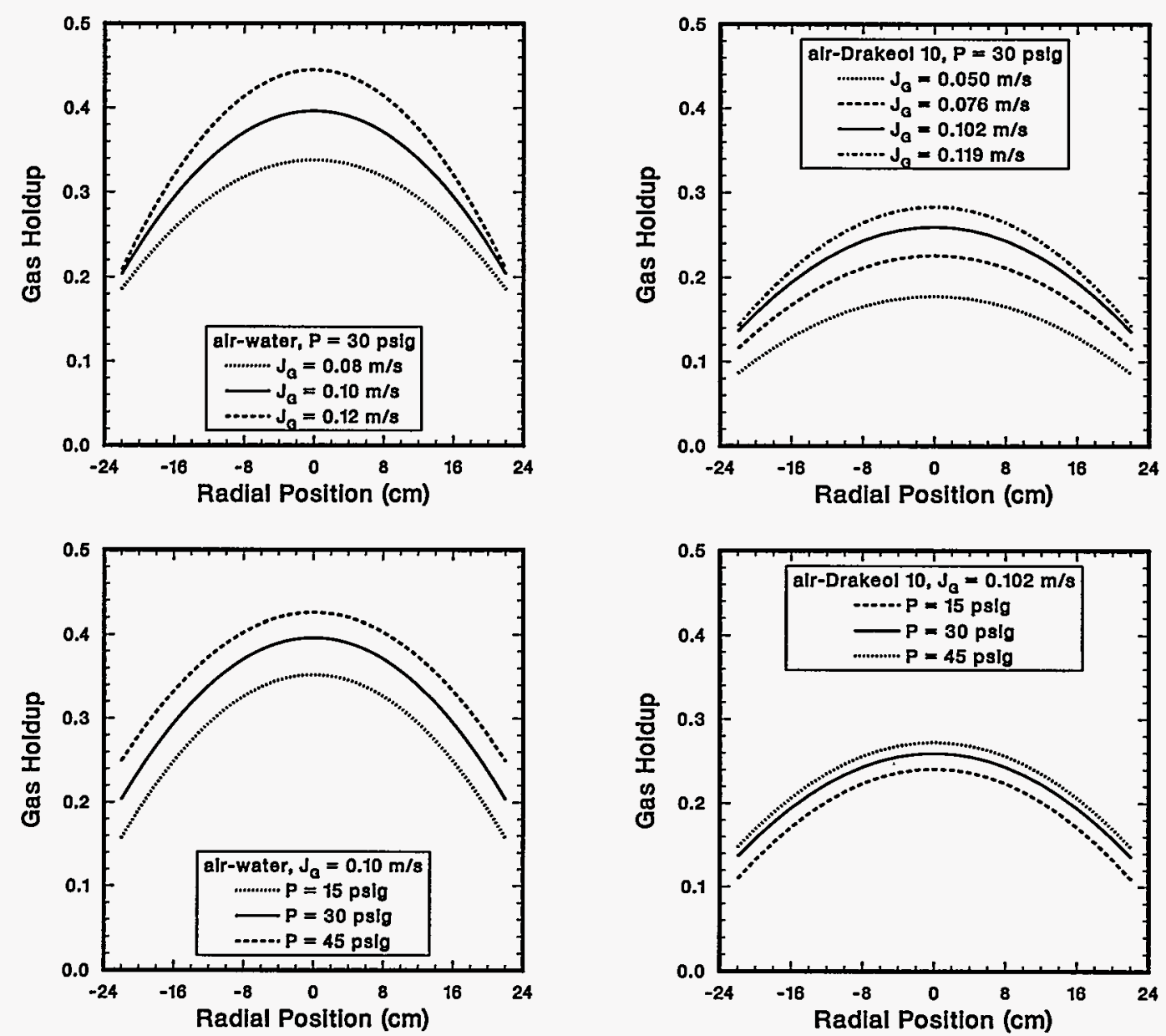

Figure 4. Gas holdup profiles for air-water (left) and air-Drakeol 10 (right) as functions of gas superficial velocity at fixed pressure (top) and pressure at fixed gas superficial velocity (bottom). 


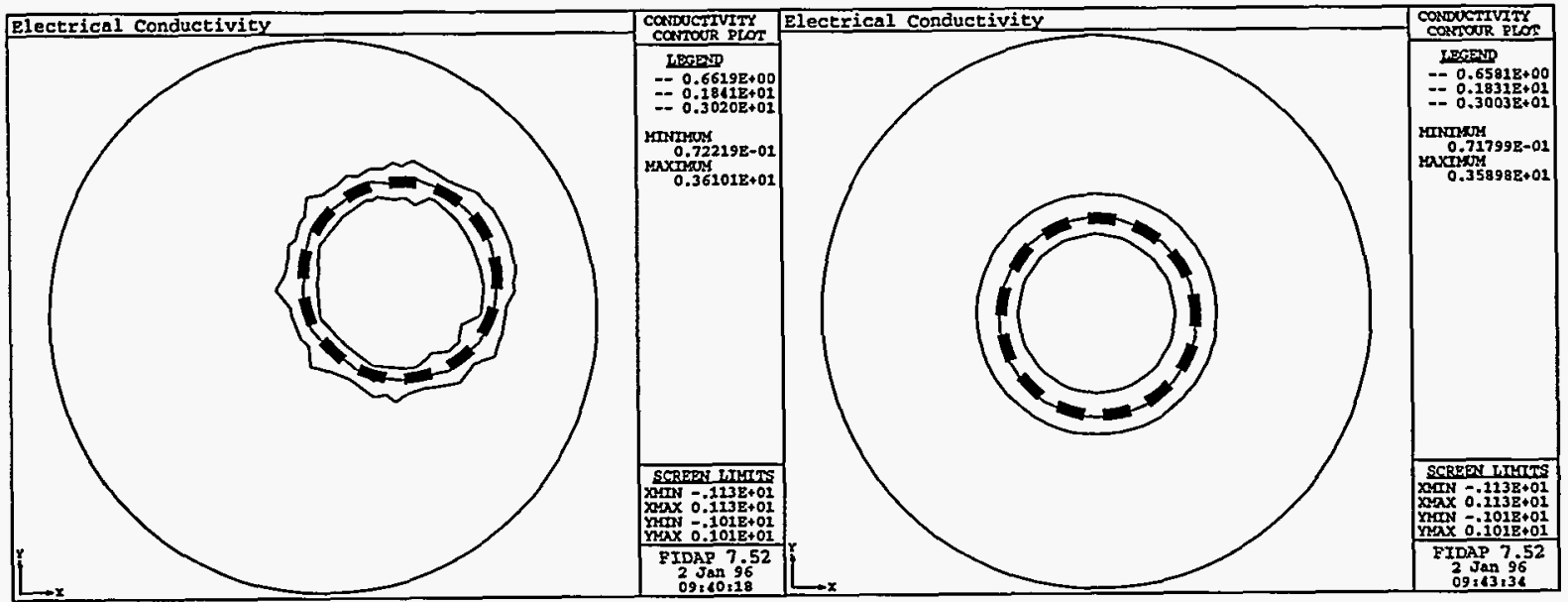

Figure 5. Reconstruction of the size and position of a PVC pipe within a lucite cylinder: dashed line indicates PVC position and size; contours show reconstruction. Left, eccentric placement. Right, concentric placement. Irregularity of the eccentric reconstruction is an artifact of the FEMEIT finite-element mesh.
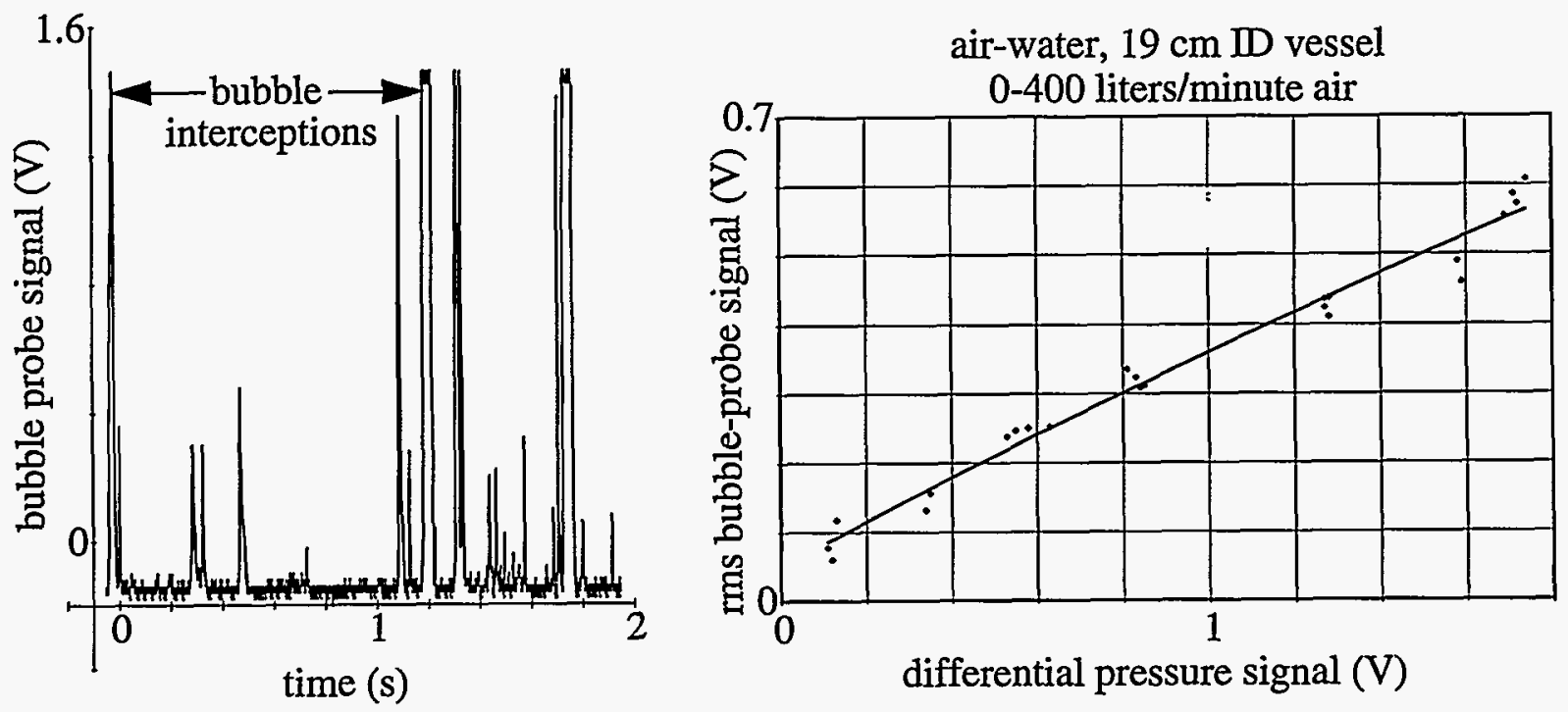

Figure 6. Electrical-conductivity bubble probe results. Left, voltage history showing times during which the probe intercepts bubbles. Right, correlation of the bubble probe mean voltage with the differential pressure signal.

\section{DISCLAIMER}

This report was prepared as an account of work sponsored by an agency of the United States Government. Neither the United States Government nor any agency thereof, nor any of their employees, makes any warranty, express or implied, or assumes any legal liability or responsibility for the accuracy, completeness, or usefulness of any information, apparatus, product, or process disclosed, or represents that its use would not infringe privately owned rights. Reference herein to any specific commercial product, process, or service by trade name, trademark, manufacturer, or otherwise does not necessarily constitute or imply its endorsement, recommendation, or favoring by the United States Government or any agency thereof. The views and opinions of authors expressed herein do not necessarily state or reflect those of the United States Government or any agency thereof. 